\section{Biases in the Assimilation of Technological} Breakdowns: Do Accidents Make Us Safer?

\author{
S. PLOUS ${ }^{1}$ \\ Department of Psychology \\ Wesleyan University
}

Field surveys and anecdotal evidence suggest that supporters and opponents of a given technology tend to draw opposite conclusions from noncatastrophic breakdowns. Three studies confirmed this tendency by presenting supporters and opponents of a particular technology with identical descriptions of various technological breakdowns. As predicted, the results indicated that (a) supporters focused on the fact that the safeguards worked, while opponents focused on the fact that the breakdown occurred in the first place; and (b) after reading about the breakdown, supporters reported feeling that the chances of a catastrophic acciden were less than previously assumed, whereas opponents reported feeling that the chances of an accident were greater than previously assumed. The recommendation by Lord Leper, and Preston (1984) for partisans to consider opposite outcomes such as a serious failure in safeguards or the absence of major comes such as a serious falure in safeguards or the absence of major breakdowns- was discussed as a way of preventing biased assimilation and at titude polarization.

On June 3rd, 1980, officers at the Strategic Air Command (SAC) were routinely watching for signs of a Soviet nuclear missile attack. The shift had thus far passed uneventfully, and there were no signs of what was about to happen.

Suddenly, a computer display warned that the Soviets had just launched a sortic of land- and submarine-based nuclear missiles. In several minutes, the missiles would reach the United States.

SAC responded immediately. Across the country, more than 100 nuclear-armed B-52 bombers were put on alert and prepared for takeoff. Nuclear submarine commanders were also alerted, and missile officers in underground silos inserted their launch keys into position. The United States was ready for nuclear war.

Then, just 3 minutes after the warning had first appeared, it became clear that the alert was a false alarm. American forces were quickly taken

${ }^{1}$ This research was supported in part by an SSRC-MacArthur Foundation Fellowship in International Peace and Cooperation. The author would like to thank Catherine Jovicich for acting as experimenter in Study 1 and Study 3. The author is also grateful to Kim Bartholomew, Mark Lepper, Lincoln E. Moses, Scott Sagan, and Philip G. Zimbardo for their comments on an earlier draft.

Please direct all correspondence to S. Plous, Department of Psychology, Wesleyan University, Middletown, CT 06459.

\section{8}

Journal of Applied Social Psychology, 1991, 21, 13, pp. 1058-1082. Copyright $C 1991$ by V.H. Winston \& Son, Inc. All rights reserved. off alert, and a number of investigations were initiated. Following a second false alert several days later, the Defense Department located the source of error. As it turned out, a computer chip worth $\$ .46$ had malfunctioned. Instead of registering the number of incoming missiles as a string of zeros, the chip had intermittently inserted 2's in the digital readout.

Given the fact that (a) the system malfunctioned and (b) the United States did not go to war despite the malfunction, the question naturally arises as to whether this breakdown indicates that we are safer or less safe than previously assumed. In a nutshell, the thesis of this paper is that people will feel less safe after a noncatastrophic technological breakdown if they already oppose the particular technology, but will feel more safe after such a breakdown if they support the technology. For example, in the case of the missile alerts, U.S. Representative Frank Horton warned that such false alarms "are a serious threat to our national security [and] could trigger an overreaction by the Soviets that could lead to nuclear confrontations," whereas General James W. Hartinger, who was Commander in Chief of the North American Aerospace Defense Command at the time of the false missile alerts, concluded that "I really have more confidence in the system now because it was demonstrated that we could cope with such a fault" (U.S. Congress, 1981, p. 131-133).

A similar reinforcement of pre-existing views took place following the near-meltdown at Three Mile Island (Mitchell, 1982; Rubin, 1981; Slovic, Fischhoff, \& Lichtenstein, 1982; Weinberg, 1981). After this incident, the U.S. House Science and Technology Committee wrote that: "Antinuclear advocates have professed that Three Mile Island proves that the accident which was not supposed to happen could happen. Hence, assurances about nuclear safety should not be believed. However, the hearings record shows this is not the case... A serious powerplant accident is now even less likely to happen, and moreover, if an accident does occur, the chances are lower that there will be a release of dangerous amounts of fission products to the environment" (U.S. Congress, 1980a, p. 32, 18).

As Mazur (1981b) concluded in his survey of 42 scientists who had publicly advocated or opposed nuclear power development before the accident at Three Mile Island: "None of the prominent scientists discussed here realigned themselves on the nuclear issue because of Three Mile Island... Most respondents interpreted the accident to fit into their preconceptions about nuclear power. Thus, opponents tended to see it as 
a near catastrophe, symptomatic of the inability of private corporations and government regulators to manage reactors in a safe manner. Proponents emphasized that no one was killed; that the radiation release was relatively small, and therefore the safety system worked" (p. 220221) (see Table 1). Each side assimilated the evidence in keeping with its own biases; nuclear energy opponents tended to be upset by the very occurrence of a serious breakdown and tended to view the breakdown as proof that a future catastrophe would occur, whereas nuclear energy supporters tended to be reassured by the safeguards and tended to believe that future catastrophes would be averted.

Laboratory research also suggests that biases in assimilation can lead to attitude polarization. Lord, Ross, and Lepper (1979) presented supporters and opponents of capital punishment with two contrived studies on the deterrent efficacy of the death penalty, one with evidence supporting capital punishment and one with evidence opposing it. For half of the subjects, the mock prodeterrence study employed a "before-after" design and the mock antideterrence study used an "adjacent-states" design. For the other subjects, these designs were reversed. The results indicated that (a) subjects tended to rate the study which supported their pre-existing position as methodologically superior to the study which opposed their views, and (b) previous differences of opinion between proponents and opponents widened as a result of exposure to the two studies.

Unfortunately, experiments have not yet been conducted on whether biases in assimilation can lead to a polarization in technological risk estimates. Although several anecdotal reports are consistent with an interpretation of biased assimilation mediating attitude polarization, they may also be a function of selective media exposure or the role requirements imposed on public figures. To control for these factors, three studies were conducted in which respondents of differing political persuasions read identical descriptions of noncatastrophic technological breakdowns.

In Study 1, students who strongly favored or opposed nuclear energy read excerpts concerning the accident at Three Mile Island, and students who strongly favored or opposed nuclear deterrence read excerpts concerning the 1980 false missile alerts at SAC. Two hypotheses were advanced:

Biased Assimilation-Supporters of a given technology will focus on the fact that the safeguards worked, while opponents will focus on the fact that the breakdown occurred in the first place.
Attitude Polarization-Supporters will report feeling safer after reading the description, will be more inclined to support the technology henceforth, and will conclude that the chances of a catastrophic accident are less than they previously thought, whereas opponents will report feeling less safe, will be less inclined to support the technology in the future, and will conclude that the chances of a future accident are greater than they thought.

Study 2 replicated and extended the findings of Study 1 by presenting the false missile alert excerpts from Study 1 to ROTC cadets (who tended to favor nuclear deterrence) and peace activists (who tended to oppose nuclear deterrence). Finally, Study 3 used a correlational design to examine whether technological breakdowns lead to biased assimilation and attitude polarization among individuals who are not selected for having extreme positions.

Study 1

\section{Method}

Participants. A total of 215 students in Introductory Psychology completed a long series of questionnaires, one of which included four questions on advocacy of nuclear energy, four questions on advocacy of nuclear deterrence, one question on whether there had ever been a major nuclear power plant accident, and one question on whether there had ever been a false alert in which American warning systems erroneously indicated a missile attack. As much as possible, these questions were culled or adapted from national opinion polls on nuclear energy and nuclear deterrence (Gallup, 1987; Public Agenda Foundation, 1984), and in keeping with the definition of technological advocacy suggested by Mazur (1981a, p. 62), the elements of need, effectiveness, and safety were emphasized. The four advocacy items for each issue consisted of statements such as "Nuclear power is necessary in order to meet today's growing demand for energy" or "As things stand, the United States is safer with nuclear weapons than without them," followed by 5 point scales ranging from "Strongly Agree" to "Strongly Disagree."

One to five weeks later, 43 of these students were contacted to participate for course credit in an experiment on "how people make subjective likelihood estimates of uncertain events." Based on their additive four-item advocacy scores (ranging from a low of 4 to a high of 20), 9 students were identified as strong supporters of nuclear energy 
$(M=19.3)$ and 11 were classified as strong opponents of nuclear energy $(M=5.3)$. Similarly, 13 students were categorized as strong supporters of nuclear deterrence $(M=19.5)$ and 10 were classificd as strong opponents of nuclear deterrence $(M=4.9)^{2}$. Thus, 20 subjects were assigned to the nuclear energy condition, and 23 subjects were assigned to the nuclear deterrence condition. Eighty-six percent of the subjects who supported nuclear energy or nuclear deterrence were male, compared with only $43 \%$ of those who opposed nuclear energy or deterrence. This gender difference in nuclear advocacy is consistent with past research (Eiser, Spears, \& Webley, 1989; Plous, 1989) and will be discussed in Study 2.

Procedure. Subjects were seen individually by a female experimenter who was informed whether they were to receive experimental materials on nuclear energy or nuclear deterrence but was blind to whether subjects were classified as supporters or opponents. The experimenter told subjects that the study was an experiment on how people perceive issues of safety and risk. Depending on experimental condition, subjects were asked to read a three-page binder of excerpts concerning either the 1979 nuclear reactor accident at Three Mile Island or the 1980 false missile alert at SAC. These events were chosen because of their previously noted tendency to polarize attitudes and because of their societal importance. The excerpts were selected to present both a balanced factual overview of each breakdown and a sampling of common reactions to it. Each binder began with an abbreviated New York Times article on the accident (Halloran, 1980; Lyons, 1979); on the second page, the binders included an extended passage taken from a prominent summary report (Perrow, 1981; U.S. Congress, 1980b); and on the final page, the binders contained multiple excerpts from U.S. congressional testimony (U.S. Congress, 1979; 1981).

Subjects were told that they would be quizzed for comprehension and that they should read the materials as carefully as possible. In this study and the following two studies, subjects finished reading the stimulus materials in approximately 10 minutes and were prevented from referring back to the excerpts thereafter. The students then completed a four-question, multiple choice quiz which included questions on what had caused the breakdown, what the consequences of the

\footnotetext{
${ }^{2}$ Three subjects were strong opponents of both nuclear energy and nuclear deterrence, and one subject was a strong supporter of nuclear energy and nuclear deterrence. So as to equalize the number of subjects in each experimental condition, the opponents of nudear energy and deterrence were assigned to the nuclear deterrence condition, and the supporter of nuclear energy and deterrence to the nuclear energy condition.
}

accident were, and so forth. For example, a typical question on nuclear power asked students whether the accident at Three Mile Island resulted in (a) the death of approximately 200 people and the hospitalization of more than 1000 people for radiation sickness, (b) a statewide evacuation of Pennsylvania, or (c) the exposure of 15 plant workers to an unexpected level of radioactivity, and an average dose to the surrounding population of less radiation than given off by a chest $X$-ray. Participants in Study 1 averaged 3.9 items correct, so it may be assumed that they read the materials thoroughly.

Dependent measures. After the quiz, students were asked to list what conclusions, if any, could be drawn from the breakdown, and what influence, if any, the breakdown had on their opinion concerning the safety of nuclear power/nuclear weapons. These open-ended questions were intended to elicit opinions without directing attention to particular aspects of the breakdown (e.g., that the safeguards worked) or to particular inferences which might be made (e.g., that the probability of a future accident had changed). Following these free responses, students answered several forced-choice questions designed to assess attitude change: (a) Whether they now had greater faith that safeguards would work in the event of a future accident, less faith, or had experienced no change in opinion; (b) whether they were now more inclined to support the development of nuclear power/increases in defense spending, less inclined, or had experienced no change in opinion; and (c) whether they now saw the chances of a catastrophic accident (a major nuclear power accident involving several hundred thousand deaths/a nuclear war triggered by an accident or mistake) as more likely, less likely, or had experienced no change in opinion.

These three measures were scored as $+1,0$, or -1 (where +1 indicated a pronuclear change, 0 indicated no change, and -1 indicated an antinuclear change) and were combined to form an unweighted composite index of change in advocacy (composite attitude change scores in Study 1 ranged from -3 to +3 , with a mean not significantly different from 0 $[M=-.12]$ and a standard deviation of 1.38). Students also answered whether the safeguards in a given situation had been adequate (on a 9 point scale ranging from "Not Adequate At All" to "Completely Adequate") and whether the accident had been a serious one (on a 9 point scale ranging from "Not Very Serious" to "Extremely Serious"). Finally, the experimenter debriefed subjects as to the purpose of the study, thanked them for their participation, and asked that they not reveal any details of the experiment to other students. 


\section{Results and Discussion}

Biased assimilation. As can be seen from the sample of free responses contained in Table 1, pronuclear students interpreted the breakdowns quite differently than students who had previously opposed nuclear energy or nuclear deterrence. Pronuclear students tended to view the breakdowns as successful tests of system safeguards, while antinuclear students tended to perceive the breakdowns as evidence of system vulnerability. Because none of the central dependent variables differed significantly between subjects in the nuclear energy condition and subjects in the nuclear deterrence condition, these two conditions will be combined hereafter to form two general groups, one "pronuclear" and the other "antinuclear." On the average, pronuclear subjects regarded the breakdowns as far less serious $(M=4.1)$ than did antinuclear subjects $(M=6.9), t(41)=5.15, p<.001,{ }^{3}$ and they tended to see the safeguards as much more adequate $(M=6.3)$ than did their antinuclear counterparts $(M=3.8), t(41)=4.37, p<.001$.

In addition, biased assimilation was apparent in the ease with which subjects' responses to the stimulus materials could be categorized as pronuclear or antinuclear. Complete response protocols for all $43 \mathrm{sub}$ jects were given to a judge who was unaware of subjects' prior attitudes, and in every instance, the judge was able to accurately classify subjects as previously pronuclear or antinuclear. These results strongly support the hypothesis that pronuclear subjects and antinuclear subjects interpret technological breakdowns in distinctly different ways.

Attitude polarization. As Table 2 shows, prior differences in attitude between pronuclear subjects and antinuclear subjects were strengthened following exposure to the stimulus materials. Students who already supported nuclear energy or nuclear deterrence averaged +.64 on the composite index of change in advocacy, $t(21)=3.13, p<.006$, whereas antinuclear subjects averaged -.90 on the index, $t(20)=3.10, p<.006$. Furthermore, chi-square analyses showed that pronuclear subjects and antinuclear subjects differed on the individual attitude items concerning faith in safeguards, $\chi^{2}(2)=9.93, p<.008$, and future support for nuclear energy or nuclear deterrence, $\chi^{2}(2)=14.85, p<.001$. Relative to pronuclear subjects, antinuclear subjects were more likely to report losing faith in safeguards following a breakdown, and they were less likely to support the development of nuclear energy or future increases in defense spending. Pronuclear subjects and antinuclear subjects did

\footnotetext{
${ }^{3} \mathrm{All} p$ values in this article are based on two-tailed tests of significance.
}

not differ significantly on the final item of the composite index, however, $\chi^{2}(2)=3.83, p<.15$. Although the pattern of change was in the predicted direction, only a minority of students felt the chances of a future catastrophe had changed as a result of the breakdown.

Thus, while two of the self-report measures were consistent with attitude polarization, the evidence for technological breakdowns leading to polarization in subjective likelihood estimates was weak at best. In addi tion, Study 1 suffered from a number of limitations. First, the population of subjects was limited to students in Introductory Psychology. Second, the questionnaire used in subject selection had not been previously tested for criterion or construct validity, and may have simply identified subjects who habitually give extreme opinions. Third, the outcome measures of biased assimilation did not explicitly contrast the importance of safeguards with the fact that the breakdown had occurred in the first place. Fourth, attitude polarization was examined for only two breakdowns, the accident at Three Mile Island and the false missile alerts at SAC, both of which were already known to most of the subjects Finally, because subjects were seen individually by the experimenter, there may have been subtle demand pressures to indicate a strengthening of opinion following the presentation of stimulus materials.

To overcome these limitations, surveys in a second study were group-administered to staff members from two national peace organizations and to ROTC cadets training to become officers in the United States Air Force. Study 2 used the same experimental design and written excerpts on false missile alerts that were used in Study 1, supplemented by four additional breakdowns - all serious, but none well known-and several new measures of biased assimilation and attitude change.

Study 2

\section{Method}

Participants. A total of 45 subjects participated in Study 2. Twentyfour ROTC cadets from San Jose State University (19 male and 5 female) constituted the prodeterrence group. The antideterrence group was composed of 14 staff members ( 3 male and 11 female) from the national headquarters of Beyond War, and 7 staff members ( 1 male and 6 female) from the national headquarters of Physicians for Social Responsibility.

${ }^{4}$ The author is indebted to these subjects, none of whom received course credit or finan cial compensation for their participation. 
Table 1

Excerpted Free Responses from Mazur (1981) and Study 1

Expert Responses to Three Mit
Preoiously Pro-Nuclear
"It is clear that human crrors can never
be complctely excluded but the very fact
that, even under the circumstances, no
damage to health or life has been done at-
tests to the high quality of nuclear reactors."
"I still believe nuclear power for the
generation of electricity is needed and is
safer than the other major alternate -
coal."
"Public fears have been exaspcrated
lsicl by the past Three Mile Island event,
but only in the minds of those who are
uninformed... There is nothing in the ex-
perience of Three Mile Island that dis-
courages me in the slightest."

"My views with respect to nuclear energy...have certainly been reinforced by Three Mile Island and what has ensued." energy." some time."

Table 1 (Continued)

$$
\text { Student Responses to Three Mile Island: Study } 1
$$

Preoiously Pro-Nuclear

"Nuclear power is safe in that the safety features built in to the Three Mile Island reactor functioned correctly in automatically shutting down the reactor before any more radiation was emitted, despite errors in judgment made by the plant's operators."
Previously Anti-Nuclear

"Those in control of power plants suffer from a laissez-faire attitude. More precisely, it seems that officials of nuclear power plants require large scale accidents or nearmisses in order to recognize inevitable problems such as equipment, design, and labor failure."

"l still hold a negative opinion about nuclear reactors as a long-range source of

"My own opinions in this matter were largely shaped by reports prepared by trusted scientists who had devoted a great deal of time to analyzing the scientific is sues involved. The Three Mile Island accident had the effect of proving that their contentions were correct.

"I have seen little reason to change the view of nuclear power that I have had for

Student Responses to Three Mile Island: Study 1

Preoiously Pra Nuclear

"The fact that the safeguards worked and the accident wasn't more serious makes me feel that a more serious accident could be prevented."

"It has made me feel as though nuclear power is safer than I thought it was. Before the accident, the production of nuclear power was not something that I was familiar with, and I thought that if an accident ever happened, it would be much worse than it was at Three Mile Island."

\section{Preoiously Anti-Nuclear}

"Three Mile Island demonstrated that it is just too risky to build nuclear power plants."

"I have always thought that nuclear power was unsafe. Actually, I never even knew about the accident at Three Mile Is land until it was echoed by the recent disaster at Chernobyl. It was really the accident at Chernobyl that made me distrust the safety of nuclear power plants."

Student Responses to False Missile Alerts: Study 1

Preoiously Pro-Nuclear

"If any conclusion can be drawn at all, it is that the U.S.'s nuclear response system is highly complex and that because of the many safeguards built into the system, an erroneous nuclear response by the U.S. is unlikely."

"When I first heard about these false alert incidences [sic] I think that it really reassured me I was relieved to know that we have something besides computers."

"I had heard about these alerts before, so I can't really say that they changed my opinions. They probably reinforced my opinions about the necessity of nuclear deterrence and the relative safety of our system."

"The successful outcome of the false alerts indicates that we are ready to deal with false alerts efficiently and intelligently."

\section{Preoiously Anti-Nuclear}

"I feel that such computer failures increase the chances of having a nuclear war. If a malfunction were to occur, both the Soviets and we could take precautionary measures which could escalate to cause firing of missiles."

"The false alerts are merely confirmations of what was apparent earlier: nuclear weapons are dangerous because of their horrible, immense, irreversible, and immediate power."

"I had not realized that such malfunctions had in fact occurred. These false alerts have decreased my confidence in our warning system. I feel now that our nuclear weapon system is less safe than I thought before."

"The false alerts proved to the public what computer professionals were already aware of: computer systems, especially large-scale ones such as the defense system, are prone to mistakes."

Note. I wish to thank Allan Mazur for granting access to his survey protocols. 
Table 2

Attitude Change as a Function of Previous Position: Studies 1 and 2

\begin{tabular}{|c|c|c|c|}
\hline \multirow{3}{*}{ Attitude Change } & \multicolumn{3}{|c|}{ Study 1} \\
\hline & \multicolumn{2}{|c|}{ Previous Position } & \multirow{2}{*}{ Total } \\
\hline & Pronuclear & Antinuclear & \\
\hline In Favor & 11 & 2 & 13 \\
\hline No Change & 10 & 9 & 19 \\
\hline Against & 1 & 10 & 11 \\
\hline \multirow[t]{2}{*}{ Total } & 22 & 21 & 43 \\
\hline & \multicolumn{3}{|c|}{ Study 2} \\
\hline \multirow[t]{2}{*}{ Attitude Change } & \multicolumn{2}{|c|}{ Previous Position } & \multirow{2}{*}{ Total } \\
\hline & Pronuclear & Antinuclear & \\
\hline In Favor & 14 & 1 & 15 \\
\hline No Change & 8 & 11 & 19 \\
\hline Against & 2 & 9 & 11 \\
\hline Total & 24 & 21 & 45 \\
\hline
\end{tabular}

Note. Cell frequencies reflect the number of subjects whose attitudes changed in a given direction (based on a three-item composite index of change).

In all, then, Study 2 included 24 prodeterrence subjects and 21 antideterrence subjects.

Procedure. Three group sessions were conducted, one for each peace organization and one for the ROTC cadets. The experimenter informed each group that the study was an experiment on how people think about technological breakdowns. Subjects were given a survey packet which contained six sections: (a) The same four items used in Study 1 to measure nuclear deterrence advocacy; (b) the excerpts concerning false missile alerts that were used in the nuclear deterrence condition of Study 1 ; (c) the reading comprehension quiz used in the nuclear deterrence condition of Study 1 (both the prodeterrence and antideterrence subjects in Study 2 a veraged 3.7 items correct out of 4 , so it may be assumed that subjects read the materials carefully); (d) the same forcedchoice measures of biased assimilation and attitude change used in the nuclear deterrence condition of Study 1; (e) four new scenarios describing technological or human breakdowns in the American and Soviet military; and (f) two general questions, one on whether serious breakdowns led to greater confidence that an inadvertent nuclear war would not occur, less confidence, or neither; and one concerning which aspect of a breakdown was most important in assessing the chances of an inadvertent war-that the safeguards worked as planned, or that the breakdown happened in the first place. Thus, only the last two sections departed significantly from Study 1.

In the section that added four new descriptions of technological or human breakdowns, subjects were asked to suppose that the following scenarios took place: (a) "Two American Air Force officers conduct a simulation test of a nuclear missile, but because of an error by the maintenance crew, the missile begins to execute an actual launch sequence"; (b) "The Soviet Union launches a missile which unexpectedly begins heading toward Alaska"; (c) "A member of the United States Coast Guard sends a phony message to ships at sea, announcing that the President has been assassinated and that the Vice President has declared World War III"; and (d) "A low-ranking officer at Soviet Pacific Fleet Headquarters sends a false alert to Soviet naval forces, declaring a state of war with the United States and ordering ship commanders to prepare to engage American forces in combat."

Each scenario was followed by three questions. First, subjects were asked to indicate on a 9 point scale ranging from "Virtually Impossible" to "Quite Possible": "If an event like this occurred, what are the chances that it could lead the superpowers into an accidental or inadvertent nuclear war?" Next, subjects were asked how the episode would affect their confidence in the safety of nuclear deterrence (on a 9 point scale ranging from "I Would Lose Confidence" to "I Would Gain Confidence") if the event ended as follows: [Scenario 1] "The error is detected immediately, the plug is pulled, and the missile is stopped from launching"; [Scenario 2] "The Soviets quickly realize their mistake and successfully destroy the missile in flight"; [Scenario 3] "The Coast Guard District Office recognizes the announcement is not legitimate 
and instantly notifies all ships to disregard the earlier message"; and [Scenario 4] "Soviet ship commanders contact headquarters to verify the message, and 20 minutes later they learn that the war alert is a false alarm." Finally, subjects indicated whether, to the best of their knowledge, such an event had ever taken place.

In the concluding section of the survey packet, subjects were informed that: "Each of the episodes described on the previous two pages has in fact occurred:

- On November 19, 1980, a Titan missile at McConnell Air Force Base began an actual launch sequence during a reliability test.

- Former Soviet leader Nikita Khrushchev reportedly once admitted that an erratic Sovict missile had to be destroyed in flight as it headed toward Alaska.

- On February 27, 1971, an enlisted member of the U.S. Coast Guard transmitted a phony declaration of World War III and was subsequently confined for medical evaluation.

- On August 13, 1984, an officer of the Soviet Far Eastern Army sent Soviet naval forces a coded signal announcing that 'We are going into a state of war with the United States.'

In each of these episodes, certain safeguards prevented what may have otherwise become an accidental or inadvertent war."

Subjects then answered two last questions: (a) "Several serious human and technological breakdowns have taken place without leading to nuclear war between the superpowers. Do such breakdowns give you greater confidence that an inadvertent nuclear war will not occur in the future, less confidence, or neither?"; and (b) "When a human or technological breakdown occurs, which factor is more significant in assessing the likelihood of an inadvertent nuclear war in the future-that the safeguards worked as planned, or that the breakdown happened in the first place?" All subjects were asked to complete the survey packet without speaking to one a nother.

\section{Results and Discussion}

Validity checks. According to an unweighted composite measure of nuclear deterrence advocacy formed by adding together the four relevant items from the first section of the survey packet, prodeterrence subjects were indeed more supportive of nuclear deterrence $(M=15.3)$ than were antideterrence subjects $(M=6.6), t(43)=11.51, p<.001$. These advocacy scores are comparable to those found in Study 1 . As intended most subjects were also unaware of the four new technological and human breakdowns described in Study 2 . Seventy-eight percent had not heard of the first breakdown, and more than 95 percent had not heard of the other three breakdowns.

Biased assimilation. Once again, prodeterrence subjects and antideterrence subjects differed in how they perceived the false missile alert at $\mathrm{SAC}$. Prodeterrence subjects tended to view the breakdowns as significantly less serious $(M=5.6)$ than did antideterrence subjects $(M=$ $8.1), t(43)=4.48, p<.001$, and they tended to regard the safeguards as far more adequate $(M=6.8)$ than did the antideterrence subjects $(M=3.9)$, $t(43)=6.35, p<.001$. These findings directly replicate the results of Study 1 .

Prodeterrence and antideterrence subjects also differed in their estimates of whether the four new breakdowns could lead to an accidental or inadvertent nuclear war. In each instance-whether the breakdown was American or Soviet, mechanical or human-prodeterrence subjects rated the chances of it leading to war as significantly less (overall $M=$ 4.4) than did antideterrence subjects (overall $M=7.3$ ), $t(43)=5.28, p<$ .001. Thus, breakdowns were treated differently by the two groups regardless of whether subjects were previously aware of the event (as in the case of the SAC alerts) or had never heard of the event before.

As seen in Table 3, prodeterrence and antideterrence subjects viewed different factors as decisive in assessing the likelihood of an inadvertent nuclear war. Prodeterrence subjects tended to emphasize the importance of safeguards, whereas antideterrence subjects tended to focus on the fact that breakdowns happened in the first place, $\chi^{2}(1)=18.26, p<.001$. These results strongly support the hypothesis of biased assimilation.

Attitude polarization. As predicted, prior attitudes toward nuclear deterrence were reinforced after subjects read about the false missile alerts (see Table 2). According to the same composite measure of attitude change that was used in Study 1 , deterrence advocacy increased $(M=$ $+1.17)$ for those subjects who were already in favor of nuclear deterrence, $t(23)=3.39, p<.003$, and declined $(M=-.86)$ for those subjects who already opposed deterrence, $t(20)=2.83, p<.02$. In addition, pronuclear subjects and antinuclear subjects differed as predicted on each of the three attitude items comprising the composite index: faith in safeguards, $\chi^{2}(2)=16.46, p<.001$; support for increased defense spending, $\chi^{2}(2)=8.95, p<.02$; and chances of a nuclear war, $\chi^{2}(2)=7.40, p<$ .03 . Compared with prodeterrence subjects, antideterrence subjects were more likely to report losing faith in the safeguards, less likely to support 
Table 3

Relative Importance of Safeguards Versus Breakdowns in Probability Estimates of Inadvertent Nuclear War: Study 2

\begin{tabular}{lccc}
\hline & \multicolumn{3}{c}{ Previous Position } \\
\cline { 2 - 4 } Most Important Factor & Pronuclear & Antinuclear & Total \\
\hline Safeguards Worked & 16 & 1 & 17 \\
Breakdown Occurred & 8 & 20 & 28 \\
\cline { 2 - 4 } Total & 24 & 21 & 45 \\
\hline
\end{tabular}

Note. Cell frequencies are based on answers to the following question: "When a human or technological breakdown occurs, which factor is more significant in assessing the likelihood of an inadvertent nuclear war in the future-that the safeguards worked as planned, or that the breakdown happened in the first place?"

future increases in defense spending, and more likely to see an increase in the chances of an accidental or inadvertent nuclear war. These findings replicate Study 1 and support the hypothesis that technological breakdowns will lcad partisans to opposite conclusions about the probability of future catastrophes.

As Table 4 shows, prodeterrence subjects and antideterrence subjects differed sharply in the general lessons they drew from serious breakdowns, $\chi^{2}(2)=25.83, p<.001$. Most prodeterrence subjects reported that human and technological breakdowns gave them greater confidence that an inadvertent war would not occur in the future, whereas the majority of antideterrence subjects reported that such breakdowns diminished their confidence. This difference was also partially reflected in reactions to the four breakdowns added in Study 2. In each of the four cases, antideterrence subjects indicated that the event would lead them to lose confidence in the safety of nuclear deterrence (overall $M=3.5$ ), $t(20)=4.20, p<.001$. Prodeterrence subjects, on the other hand, showed no change in confidence (overall $M=5.0$ ), $t(22)=.18$, ns.

Gender differences. In both Study 1 and Study 2, most pronuclear subjects were male and most antinuclear subjects were female. The
Table 4

The Effect of Breakdowns on Confidence as a Function of Prior Position: Study 2

\begin{tabular}{lccr}
\hline & \multicolumn{3}{c}{ Previous Position } \\
\cline { 2 - 4 } & Pronuclear & Antinuclear & Total \\
\hline Greater Confidence & 16 & 0 & 16 \\
No Change & 5 & 4 & 9 \\
Less Confidence & 3 & 17 & 20 \\
\cline { 2 - 4 } Total & 24 & 21 & 45 \\
\hline
\end{tabular}

Note. Cell frequencies are based on answers to the following question: "Several serious human and technological breakdowns have taken place without leading to nuclear war between the superpowers. Do such breakdowns give you greater confidence that an inadvertent nuclear war will not occur in the future, less confidence, or neither?"

question naturally arises, then, whether attitude polarization is less a function of previous attitudes than of the subject's gender. If so, there should be significant differences between male and female subjects after controlling for their previous position on nuclear power or nuclear deterrence. Although there were too few pronuclear female subjects to examine this hypothesis in either study alone, an aggregate test was made by combining subjects from both studies and conducting a $2 \times 2$ (Initial Attitude $\times$ Gender) analysis of variance on scores from the composite index of attitude change. ${ }^{5}$ The results showed a highly significant main effect for previous position, $F(1,84)=28.61, p<.001$, but no significant effect for the gender of subjects, $F(1,84)=.12$, ns, or gender-position interaction, $F(1,84)=.31$, ns. Thus, attitude polarization was not simply a function of the gender of subjects.

Taken together, Study 1 and Study 2 suggest that groups on either side of an issue may assimilate noncatastrophic technological breakdowns in ways that reinforce previous differences of opinion. It is

${ }^{5}$ An unweighted means approach was used, though it should be noted that cell sizes were quite unequal. 
unclear, however, whether these effects are restricted to individuals who initially hold extreme positions on the issue, or whether the same phenomenon occurs among people who are unfamiliar with the issue and hold less extreme opinions. There is evidence to suggest, for example, that attitude polarization is attenuated when subjects are relatively uninvolved or unfamiliar with a given domain (Chaiken \& Yates, 1985; Tesser, 1978; Tesser \& Leone, 1977).

Accordingly, a third study was conducted to examine whether technological breakdowns lead to biased assimilation and attitude polarization among individuals who do not hold unusually extreme positions. Unlike the earlier two studies, Study 3 was correlational in design and included mcasures on issue involvement and strength of conviction. A survey packet with the Three Mile Island stimulus materials from Study 1 was administered to a group of students whose positions on nuclear energy were normative for that age category, and the correlations among nuclear energy advocacy, strength of conviction, prior issue involvement, and attitude change were subsequently assessed.

Study 3

Method

Participants. Subjects were drawn from the same Introductory Psychology class that took part in Study 1, except that the 43 extremely pronuclear or antinuclear students who had participated in Study 1 several weeks earlier were excluded from the present subject pool. A total of 63 students, 42 male and 21 female, were randomly chosen to participate in Study 3 for course credit.

Procedure. Eight sessions were conducted with groups of between 2 and 12 subjects. The experimenter informed subjects that the study was an experiment on "how people make subjective likelihood estimates of uncertain events." Subjects were given a survey packet that opened with the following questions: (a) "In order to meet the future power needs of the nation, how important do you feel it is to have more nuclear power plants-extremely important, somewhat important, not too important, or not important at all?" (taken from Gallup [1987] and used to compare the present group of subjects with an age-adjusted national sample); (b) "All things considered, what is your position concerning the development of nuclear energy-strongly favor, mildly favor, neutral, mildly oppose, or strongly oppose?" (used as the primary index of nuclear power advocacy $\left.{ }^{6}\right) ;(c)$ "How strong are your views concerning nuclear energy?" (designed to measure strength of conviction on a labeled 5 point scale ranging from "Extremely Strong" to "Not Strong At All"); and (d) Three self-report measures of issue involvement, including how much subjects thought about nuclear energy, how much they knew about it (i.e., familiarity), and how much they talked with others about it (all on 9 point scales ranging from "Very Little" to "Quite a Bit").

After subjects answered these questions, they read the excerpts on Three Mile Island that were used in the nuclear energy condition of Study 1 . Next, they completed the same four-item reading comprehension quiz used in Study 1 (the mean number of correct responses was 3.9) and the same forced-choice measures of biased assimilation and attitude change. Finally, subjects answered two questions that were added to assess whether nuclear power plant accidents other than Three Mile Island would lead to biased assimilation and attitude polarization. In the first item, subjects indicated how much the Soviet nuclear power plant accident at Chernobyl revealed about the safety of American nuclear power reactors (on a 9-point scale ranging from "Very Little" to "Quite A Bit"). In line with the biased assimilation hypothesis and the results of a recent investigation by Eiser et al. (1989), it was predicted that to the extent subjects opposed nuclear energy, they would see the Chernobyl accident as relevant to American nuclear reactor safety. The second question asked subjects whether the Chernobyl accident demonstrated that nuclear power plants in the United States are much less safe than previously assumed, somewhat less safe, somewhat more safe, much more safe, or none of the above. In keeping with the attitude polarization hypothesis, it was predicted that opponents of nuclear energy would be more likely than supporters to view the Chernobyl accident as a demonstration that American nuclear power plants are less safe than assumed, and that supporters would be more likely than opponents to see the accident as proof that American reactors are more safe than assumed. As in Study 2, subjects were instructed not to speak with one another while they completed the survey packets.

\section{Results and Discussion}

Comparison with national sample. As measured by the polling question

${ }^{6}$ Unfortunately, due to a mistake in data storage, the measures of nuclear energy advocacy used in Study 1 were unavailable for subjects in Study 3. 
taken from Gallup (1987), subjects in the present study did not differ significantly in nuclear energy advocacy from a national sample of respondents between 18 and 29 years of age, $\chi^{2}(3)=5.89, n s$.

Biased assimilation. Prior attitudes were again significantly associated with how subjects later evaluated the accident at Three Mile Island. Support for nuclear energy was positively correlated with how adequate the safeguards were seen to be, $r(61)=.38, p<.001$, and negatively correlated with judgements of how serious the accident was, $r(61)=-.30, p<$ .02. Consistent with the findings of Eiser et al. (1989), nuclear energy advocacy was also negatively related to ratings of how much Chernobyl revealed about the safety of American nuclear reactors, $r(61)=-.41, p<$ .001 . These results suggest that even among subjects who are not selected for having extreme positions, technological breakdowns may be assimilated so as to reinforce previous views.

The evidence for biased assimilation was weaker among subjects who indicated low issue involvement or weak conviction. Issue involvement was defined as an unweighted average of three self-reports: how much subjects had thought about nuclear energy, how much they knew about it, and how much they had talked with others about it (these items correlated between .71 and .81 with each other, all $p^{\prime} s<$ .001 ). A median split ${ }^{7}$ revealed that nuclear energy advocacy among low-involvement subjects was not significantly related to ratings of the adequacy of safeguards, $r(30)=.17, p>.20$, seriousness of the accident, $r(30)=-.30, p<.10$, or relevance of Chernobyl to American nuclear reactor safety, $r(30)=-.29, p=.10$. In contrast, nuclear energy advocacy a mong high-involvement subjects correlated significantly with ratings of the adequacy of safeguards, $r(29)=.60, p<.001$, relevance of Chernobyl to American nuclear reactor safety, $r(29)=-.48, p<.02$, and to some extent, seriousness of the accident, $r(29)=-.33, p<.08$.

Similarly, nuclear energy advocacy among subjects who did not report holding "very strong" or "extremely strong" opinions was not significantly related to the perceived adequacy of safeguards, $r(46)=.21$, $p<.15$, seriousness of the accident, $r(46)=-.24, p=.10$, or relevance of Chernobyl to American nuclear reactor safety, $r(46)=-.23, p<.15$. For subjects who reported having strong convictions, however, nuclear

${ }^{7}$ One problem with using a median split technique is that spurious differences may arise if variances in each half of the sample are significantly different from one another. To test for this possibility, the variability of responses by subjects high in involvement or conviction was compared with the variability of subjects low in involvement or conviction. No significant pattern of differences was detected. advocacy was significantly associated with ratings of the adequacy of safeguards, $r(13)=.66, p<.01$, and the relevance of Chernobyl to American nuclear reactor safety, $r(13)=-.73, p<.003$. Nuclear advocacy did not correlate significantly with perceived seriousness, $r(13)=-.41, p<$ .15 , though this finding may be attributed in part to low statistical power. ${ }^{8}$ In sum, biased assimilation was most evident among students who reported high issue involvement and strong convictions.

Attitudepolarization. Consistent with earlier studies, prior differences in nuclear energy advocacy were strengthened following exposure to the experimental materials on Three Mile Island. According to the same composite index of attitude change used in Study 1, previous support for nuclear energy was correlated with attitude change in a pronuclear direction, $r(61)=.50, p<.001$. Supporters of nuclear energy also differed from opponents in their interpretation of the Chernobyl accident, $\chi^{2}(2)=$ $9.37, p<.01$. Advocates of nuclear energy were much more likely than opponents to regard the Chernobyl accident as a demonstration of the safety of American nuclear reactors, while opponents were far more likely to view the accident as evidence of a lack of safety. These results support the hypothesis that technological breakdowns can lead to attitude polarization even when subjects are not selected for extreme previous positions.

As in the case of biased assimilation, these findings were attenuated with subjects who were uninvolved or had little conviction about the issue. Nuclear energy advocacy among uninvolved subjects correlated .45 with pronuclear attitude change, $p<.01$, compared with .72 among highly involved subjects, $p<.001$. Likewise, the correlation between nuclear energy advocacy and pronuclear attitude change was .34 among subjects with relatively weak prior convictions, $p<.02$, compared with .73 among subjects who reported having "very strong" or "extremely strong" opinions on nuclear energy, $p<.003$. Because the extremity of subjects' nuclear energy advocacy (i.e., absolute value of initial position) was moderately correlated with involvement, $r(61)=.50, p<.001$, and strength of conviction, $r(61)=.66, p<.001$, these differences cannot be attributed to subjects low in involvement or conviction having a more restricted range of attitudes than subjects high in involvement or conviction (if anything, the opposite is the case). Thus, although attitude polarization was evident among subjects with a range of previous

${ }^{8}$ Because the significance of a correlation coefficient depends on sample size, this com parison of subjects with strong opinions $(N=15)$ and weak opinions $(N=48)$ is extremely conservative. 
positions, it was greatest for students who were highly involved and strongly opinionated. ${ }^{9}$

\section{General Discussion}

In all three studies, technological breakdowns led to biased assimilation and attitude polarization even though subjects were exposed to identical descriptions of the same event and were unencumbered by role requirements to support or oppose the technology. Previous supporters of a given technology tended to focus on the fact that the safeguards worked and tended to be reassured by noncatastrophic breakdowns, whereas opponents focused on the very fact that the breakdowns occurred and tended to be disturbed that something serious had gone wrong.

Moreover, supporters and opponents used the breakdowns to arrive at different conclusions about the probability of a future catastrophe. After reading about a given breakdown, supporters reported sceing the chances of a future catastrophe as lower than before, while opponents reported seeing the chances as greater than before. ${ }^{10}$ These results were found regardless of whether the breakdown was human or mechanical, American or Soviet, energy related or military related, or previously known or unknown. Furthermore, they did not depend on whether subjects were originally identified as extreme in advocacy, were college students, or were ROTC cadets or members of a peace organization. The present findings were also consistent with past research showing that attitude polarization is strongest when subjects are already familiar

'While highly involved subjects did not differ substantially from less involved subjects in their responses to the question on whether Chernobyl demonstrated that American reactors are safe or unsafe, limitations in sample size ruled out the use of statistical tests.

${ }^{10}$ One point concerning attitude polarization should be clarified. In all three studies, attitude change was assessed by asking subjects whether their opinions had changed after reading about a given breakdown. Although this method follows in the tradition of previous research on biased assimilation and attitude polarization (cf. Lord, Lepper, \& Preston, 1984 Lord, Lepper, \& Ross, 1979), there is always the chance that perceioed changes in attitudes do not reflect actual changes in attitudes. In order to assess actual changes in attitude, a baseline position would have to be contrasted with the position taken after exposure to the stimulus materials (e.g., by forming difference scores based on subjective probability estimates of an accident). In the present case, the use of algebraic difference scores was precluded by the prospect of severe floor,ceiling and regression effects (for example, pilot tests revealed that pronuclear subjects set the odds of a future catastrophe at less than 5\%). Thus, all that can be concluded from the present studies is that subjects perceived changes in attitude in the
direction of previously held views. with a given domain (cf. Chaiken \& Yates, 1985; Tesser, 1978; Tesser \& Leone, 1977).

Although this study has focused on instances in which safeguards prevented technological breakdowns from becoming catastrophic, its conclusions may also apply to nontechnological breakdowns. Consider, for example, the Personnel Reliability Program (PRP) set up by the U.S. Department of Defense to screen unstable individuals from duties that directly involve nuclear weapons. Between 1975 and 1984, the PRP decertified an annual average of more than 5000 workers who were handling nuclear weapons: some for physical or psychosocial breakdowns, some for substance abuse, and some for breaches in conduct or competence (Abrams, 1987). As Maszak (1988) has noted, "Supporters of the program argue that the very fact that people are decertified demonstrates that the system works," whereas critics emphasize that "the decertification rate means that at any one time there are unstable people responsible for handling nuclear weapons" (p. 54). Although the breakdowns in question are not technological, these evaluations are quintessential examples of biased assimilation.

How can biased assimilation be reduced? One suggestion comes from an ingenious experiment on corrective strategies by Lord et al (1984). Subjects were exposed to the same procedure and materials used by Lord et al. (1979) in their study of biased assimilation and attitude polarization, but a new twist was added. One third of the subjects were asked to be "as objective and unbiased as possible...to weigh all of the evidence in a fair and impartial manner" (the be-unbiased condition). Another third of the subjects were asked to consider "whether you would have made the same high or low evaluations had [the evidence supported] the other side of the issue" (the consider-the-opposite condition). And in a direct replication of Lord et al. (1979), the remaining third were given no corrective strategy (the replication condition). Results indicated that only subjects who had "considered the opposite" were unbiased and unpolarized in their responses. Subjects in the other two conditions-even subjects who were explicitly asked to be unbiaseddisplayed a significant amount of biased assimilation and attitude polarization.

These findings suggest that in the case of technological breakdowns, the best corrective strategy may be for supporters to consider how they would have reacted if the safeguards had failed, and for opponents to consider how their antipathy toward a technology would be affected if breakdowns did not occur. By considering opposite outcomes, 
differences in interpretation may be reduced in much the same way that differences in attribution are moderated by empathy (Galper, 1976; Regan \& Totten, 1975). Although noncatastrophic breakdowns are unlikely to bring supporters and opponents into agreement on issues of safety and risk, the consideration of other perspectives may prevent a strengthening of previous differences.

\section{References}

Abrams, H.L. (1987). Human instability and nuclear weapons. Bulletin of the Atomic Scientists, 43, 34-39.

Chaiken, S., \& Yates, S. (1985). Affective-cognitive consistency and thought-induced attitude polarization. Journal of Personality and Social Psychology, 49, 1470-1481.

Eiser, R.J., Spears, R., \& Webley, P (1989). Nuclear attitudes before and after Chernobyl: Change and judgment. Journal of Applied Social Psychology, 19, 689-700.

Gallup, G., Jr. (1987). The Gallup Poll: Public Opinion 1986. Wilmington, DE: Scholarly Resources, Inc.

Galper, R.E. (1976). Turning observers into actors: Differential causal attributions as a function of "empathy." Journal of Research in Personality, 10, 328-335.

Halloran, R. (1980, June 6). Computer error falsely indicates a Soviet attack. New York Times, p. A14.

Lord, C.G., Lepper, M.R., \& Preston, E. (1984). Considering the opposite: A corrective strategy for social judgment. Journal of Personality and Social Psychology, 47, 1231-1243.

Lord, C.G., Ross, L., \& Lepper, M.R. (1979). Biased assimilation and attitude polarization: The effects of prior theories on subsequently considered evidence. Journal of Personality and Social Psychology, 37, 2098-2109.

Lyons, R.D. (1979, April 8). Middletown keeps count on levels of contamination. New York Times, p. E1.

Maszak, M. (1988, June). Minding the missiles. Psychology Today, pp. 52-56.

Mazur, A. (1981a). The dynamics of technical controversy. Washington, D.C.: Communications Press, Inc.

Mazur, A. (1981b). Three Mile Island and the scientific community. In T.H. Moss \& D.L. Sills (Eds.), The Three Mile Island nuclear accident: Lessons and implications. Annals of the New York Academy of Sciences (Vol. 365, pp. 216-221). New York: The New York Academy of Sciences.
Mitchell, R.C. (1982). Public response to a major failure of a controversial technology. In Sills, D.L., Wolf, C.P., \& Shelanski, V.B. (Eds.), Accident at Three Mile Island: The human dimensions (pp. 21-38). Boulder, CO: Westview Press.

Perrow, C. 91981). Normal accident at Three Mile Island. Society, 18, $17-26$

Plous, S. (1989). Thinking the unthinkable: The effects of anchoring on likelihood estimates of nuclear war. Journal of Applied Social Psychology, 19, 67-91.

Public Agenda Foundation. (1984). Voter options on nuclear arms policy: $A$ briefing book for the 1984 elections. New York: The Public Agenda Foundation.

Regan, D.T., \& Totten, J. (1975). Empathy and attribution: Turning observers into actors. Journal of Personality and Social Psychology, 32, 850-856.

Rubin, D.M. (1981). What the president's commission learned about the media. In T.H. Moss \& D.L. Sills (Eds.), The Three Mile Island nuclear accident: Lessons and implications. Annals of the New York Academy of Sciences (Vol. 365, pp. 95-106). New York: The New York Academy of Sciences.

Slovic, P., Fischhoff, B., \& Lichtenstein, S. (1982). Psychological aspects of risk perception. In Sills, D.L., Wolf, C.P., \& Shelanski, V.B. (Eds.), Accident at Three Mile Island: The human dimensions (pp. 11-19). Boulder, CO: Westview Press.

Tesser, A. (1978). Self-generated attitude change. In L. Berkowitz (Ed.), Advances in experimental social psychology (Vol. 11, pp. 290-338). New York: Academic Press.

Tesser, A., \& Leone, C. (1979). Cognitive schemas and thought as determinants of attitude change. Journal of Experimental Social Psychology, 13, 340-356.

U.S. Congress: House, Subcommittee of the Committee on Government Operations. (1981, May 19-20). Failures of the North American Aerospace Defense Command's (NORAD) Attack Warning System. 97th Congress, First Session, Washington, DC: U.S. Government Printing Office.

U.S. Congress: House, Subcommittee on Energy and the Environment of the Committee on Interior and Insular Affairs. (1979). Accident at the Three Mile Island nuclear powerplant. 96th Congress, First Session, Washington, DC: U.S. Government Printing Office.

U.S. Congress: House, Subcommittee on Energy Research and Production of the Committee on Science and Technology. (1980a, March). 
Nuclear powerplant safety after Three Mile Island. 96th Congress, Second Session, Washington, DC: U.S. Government Printing Office. U.S. Congress: Senate, Committee on Armed Services. (1980b, October 9). Recent False Alerts From the Nation's Missile Attack Warning System: Report of Senator Gary Hart and Senator Barry Goldwater. 96th Congress, Second Session, Washington, DC: U.S. Government Printing Office.

Weinberg, A.M. (1981). Three Mile Island in perspective: Keynote address. In T.H. Moss \& D.L. Sills (Eds.), The Three Mile Island nuclear accident: Lessons and implications. Annals of the New York Academy of Sciences (Vol. 365, pp. 1-12). New York: The New York Academy of Sciences. 